\title{
Application of Value Engineering Theory in Enterprise Product Design
}

\author{
Haixia Yan \\ School of Mechanical Engineering \\ Shaanxi University of Technology \\ Hanzhong, Shaanxi, China 723000
}

\begin{abstract}
This paper has proposed that the value engineering theory shall be applied in product design from the perspectives of product function design, material selection, technology and color through understanding of value engineering theory, and the analysis of importance of value engineering in enterprise product design, hoping to improve enterprise product value and create economic benefits to the largest extent.
\end{abstract}

Keywords—product design; value engineering; application

\section{INTRODUCTION}

With the continuous development of global economic integration, the enterprise competition is increasingly intense, and how to push the products with lower prices, better quality and more perfect function to the market in a timely manner and win in the competition is the main goal of the enterprise. Product innovation is the focus in the development of modern enterprise. Enterprises are committed to the construction of their own competitiveness in the process of product development, and enterprise competitiveness will ultimately be reflected on the competitiveness of enterprise's products. The important way to improve product competitiveness is to reduce cost and improve quality. Therefore it is necessary to promote and use the value engineering. Product design primarily refers to design the functions meeting users' needs, and realize the products' useful value. With the application of value engineering theory in product design, we can analyze and compare various design schemes, select the most suitable material and processing technology under the premise of satisfying users' demand for functions, to produce the products with the highest useful value and the best aesthetic value with the least amount of material and the shortest time, namely to obtain the biggest economic benefits using the lowest cost [1].

\section{ON THE IMPORTANCE OF VALUE ENGINEERING IN ENTERPRISE PRODUCT DESIGN}

Value engineering is generated along with the development of modern production under specific historical conditions, which is a soft science technology developed from rational utilization of resources. Value engineering is generated in America in 1947. Myles, who is known as "the father of value engineering", thought that this analysis method can also be used to discover and solve problems in the process of manufacturing, to find out and try to eliminate the unnecessary costs for products with same functions, to decrease the cost obviously and obtain good economic effect.

Value engineering was introduced into China since the 1980s, and it has obtained great development both in theory and practice. Value engineering has achieved great achievements in the improvement of existing products, research and development of new products, as well as in research, planning, manufacturing, process improvement, selection of materials, sales and service, etc., and then improve the economic benefits of the whole system related to the products, having important significance to enterprise's development [2]. It is an analysis method combining technology and economy, and it studies the relationship between function and cost, looking for best corresponding ratio between function and cost, to obtain the biggest economic and social benefits as far as possible with the smallest cost as far as possible. Improving the value of design object is the fundamental task and ultimate goal of value engineering. Value engineering can not only be used in enterprise's creation of new products, but also applied to the analysis and evaluation of existing products and current design scheme. At present, the value engineering has developed more scientific, systematic and perfect. It is acknowledged as an independent and effective scientific method in the field of design, process and production, and the effective method for improving product value and reducing cost.

\section{APPLiCATION CONTENT OF VALUE ENGINEERING IN PRODUCT DESIGN}

Product modeling design refers to the modeling design with the established industrial products as main object for people to survive and live as well as develop in the nature, which is the creative activity to pursue product function and useful value. And it is the emerging discipline researching art, technology as well as human material and cultural life. Industrial product modeling design consists of three elements, namely material function, artistic modeling and material and technical conditions, enabling product modeling design realize the basic principle of "practical, economic, beautiful". Practical refers to the having the advanced and prefect multiple function and ensuring the material function of products can be given to play to the largest extent, including the appropriate function scope, excellent working performance and scientific operational performance; beautiful refers to the aesthetic 
feeling reflected by the overall product, mainly including the product form beauty, structural beauty, technological beauty, material beauty as well as the strong sense of times and the rich ethnic style, etc.; economic refers to realize designing the products with the lowest cost, which can guide product modeling design using the theory of "value engineering", including appropriate application of material and technology.

\section{A. Analysis of Product Function Design}

All for the sake of users, product design should be conducted starting from the user's perspective, to improve the rationality of product design, improve product operability and maintainability, which need to consider the functions of product. Product functions can be divided into use function and appearance function by nature. Use function is guaranteed by the technical indicators indicated by product design task, while appearance function must be satisfied through modeling design. Product appearance quality is an important factor affecting its value. Products are pouring into the market and competition is increasingly fierce today, so it is particularly important to improve products' aesthetics quality and develop the fashionable and beautiful products. The so-called beauty mainly refers to the beautiful appearance of products, including the aesthetic appearance brought by the forms, color, texture and decoration and so on. On the premise of meeting products use function, the appearance function design shall be strengthened, in order to improve the value of its comprehensive function. It can be seen that the inner content and outer beauty are two aspects of product modeling design, and use function is the foundation of product design. The practical products shall be developed first in design process, and then pay attention to aesthetic design, thus the outer beauty embellishes the inner content, realizing mutual complementary, which has not only satisfied the consumers' physiological and psychological needs, but has improved the economic benefit of enterprise.

\section{B. Analysis of Product Material Selection}

Product material is the most basic elements of product and cost accounting. In the past, quite a lot of designers do not conduct value analysis in material selection design, having such drawbacks as unilaterally pursuing the features of strong and durable. Because they do not conduct analysis and evaluation on function, but just pursue higher material quality and greater insurance coefficient, so it has resulted in the potential material waste. If the designers can consciously use the value engineering, and make function analysis on the products and parts before the material selection, and then select the material that can guarantee product function with the lowest cost in cording to material performance and price, the material waste can be reduced.

\section{Analysis of Product Process}

The reasonable process design affects product performance and process cost directly. The development and application of new process has created conditions to improve product quality and reduce cost. But only pursue the technological advancement and ignore economical efficiency can also cause waste. Modeling design shall be conceived according to the practical and feasible technological conditions and process methods, namely to require designers know well about the performance of selected material and a variety of methods and characteristics of processing technology, and control the factors influencing modeling. Modeling design can be completed very well through repeated practice, to achieve the unification of technology advancement and economical efficiency. In the production of product modeling design, there are mainly three parts of processing process, assembly process and decorative process. How to reasonably choose and determine the various process methods is a key factor in modeling design, and also the key factor of whether or not the product modeling design value can be reflected very well.

\section{Analysis of Product Color}

Color design is an important part of product modeling design. If the color can be handed well in product design, it not only can make the product better, but also can coordinate or make up some deficiencies for the modeling, to better won the favor of consumers, and attain the result with half effort. Good color design plays a great role in improving the grade of product and competitiveness, coordinating the physical and psychological requirements of users and improving the work efficiency, as well as meeting people's pursuit for beauty and creating a comfortable living environment. Product color design has the characteristics of aesthetic and functional combination, for example, improving the accuracy of reading and operation of the display elements using the contract ratio can reduce accident frequency and improve the efficiency of production. Product color design of beauty is related to the technique means for obtaining color, product material texture and functional characteristics of the product. The same color can obtain different color effects using different process methods. At the same time, product color design should meet the requirement of mass production. The pigment preparation shall be more convenient and coloring process shall be simpler. So, the color of product should not only be beautiful, elegant and harmony, but also can reflect products' functional requirements and morphological characteristics, meeting the requirements of human engineering and environmental requirements as well as the principle of economy, at the same time, it should also reflect the characteristics of combination of modern science and technology with sense of the times, making the creation of product color beauty meet the modern aesthetic requirements, in order to reflect the value of using color in product modeling design.

In the final process of product design, the supply source of all the equipment required by product manufacturing shall be considered. It is closely connected with the product design. In each link, the work of supply shall be guided with the view of value analysis, and attach great importance to it, which is also an important aspect to reduce product cost. Considering equipment supply source in design can reduce the waste of manpower, material resources and financial resources with great potential of reducing cost.

\section{CONCLUSION}

Enterprise have to introduce the value engineering theory for better development, on the basis of fully value analysis of 
product function, material, process, and color, to obtain greater product value and economic benefit through improving cost with limitation, providing instructive significance for enterprise development.

\section{REFERENCES}

[1] He Xiaoming. Study on Application of Value Engineering Theory in Product Design [J]. Packaging Engineering, 2004.4

[2] Li Chunbo. New Theory of Value Engineering [M]. Beijing Institute of Economy Press, 2002.8 